\title{
The Determination of Iron, Titanium, and Nickel in Apollo 14 Samples by Cathode Ray Polarography
}

\author{
E. June Maienthal
}

\author{
Institute for Materials Research, National Bureau of Standards, Washington, D.C. 20234
}

(May 11, 1972)

\begin{abstract}
Methods have been developed and applied to the determination of iron, titanium, and nickel in Apollo 14 fine soil and rock by differential cathode ray polarography on the same sample. A $5 \mathrm{mg}$ sample was sufficient for the determination of all 3 elements. Iron and titanium were determined either directly or after cupferron separation. Nickel was determined after dimethylglyoxime separation.
\end{abstract}

Keywords: Analyses of iron, titanium, nickel; Apollo 14 lunar samples; differential cathode ray polarography.

\section{Introduction}

A review of the literature shows that a variety of analytical techniques, activation analysis, atomic absorption, emission spectroscopy, flame photometry, inert gas fusion, mass spectrometry, spectrophotometry, wet chemistry and $x$-ray fluorescence have been used in the analyses of returned lunar materials. Polarography, a technique with capabilities of contributing much to the lunar analytical program, is conspicuously absent. The usefulness of this technique, specifically differential cathode ray polarography, has been demonstrated at NBS to be applicable for all concentration levels from trace analysis to major constituent analysis in a wide range of analytical problems dealing with matrices such as high purity metals, alloys, steels, air particulates, waste water, ores, glasses, botanical material, etc. $[1-4] .^{1}$ The reliability of this technique has been verified through interlaboratory comparisons with many other techniques [1-3].

\section{Experimental Detail}

The lunar soil $(14163,159)$ received at NBS was a portion of the bulk fines sample taken at the end of EVA-1 on the Apollo 14 flight. The lunar rock $(14321,221)$ was a portion of the large football-size rock taken from Cone Crater during EVA-2 near station Cl.

Of the many elements in the lunar samples which could be conveniently done by polarography, the initial effort was to be put on iron and titanium. Previous work on these elements at different concentrations

\footnotetext{
${ }^{1}$ Figures in brackets indicate the literature references at the end of this paper.
}

was done for the certification of these elements in the new "Trace Elements in a Glass Matrix" Standard Reference Material at the $0.02-, 1-, 50-$, and 500-ppm level [5].

Iron and titanium could probably be determined directly with no separations in most types of rocks and soils; however, with a limited amount of lunar material available, repeat runs usually are not feasible should interferences be present. Both iron and titanium are easily and quantitatively extracted with cupferron and chloroform and can be determined simultaneously in an EDTA-sodium acetate supporting electrolyte. Iron is reduced at about $-0.3 \mathrm{~V}$ and titanium at about $-0.5 \mathrm{~V}$ versus a mercury pool anode.

This proposed procedure for iron and titanium was carried out on U.S. Geological Survey andesite, AGV-1. Values of 4.75 percent iron and 0.635 percent titanium were obtained on $5-\mathrm{mg}$ samples. The average values for AGV-1 given by Flanagan [6] are 4.75 percent iron and 0.649 percent titanium, although Abbey [7] recommends averages of 4.64 percent iron and 0.635 percent titanium as being more representative of the best laboratories' values. Although larger sample sizes would probably lead to more accurate results, a method for very small samples was required to use a minimum of lunar material.

All precautions possible were taken to minimize the environment and reagent blanks. The samples were processed, covered, in laminar-flow class 100 hoods for most of the operations. Certain steps of the procedure, such as weighings on the microbalance, were done in the regular laboratory atmosphere, since vibrations were too pronounced in the laminar-flow hoods. Samples transferred from hood to hood and room to room were covered with watch glasses and 
placed in boxes with an overlaying sheet of Parafilm² to protect them from contamination.

The acids and distilled water used in the procedure were purified by distillation in quartz by the NBS Analytical Mass Spectrometry Section. Polarographic analysis of the redistilled acids gave values of 2.6 parts per billion (ppb) of iron for the $9 M$ hydrochloric acid and $1.4 \mathrm{ppb}$ for the nitric acid.

The iron fallout in the laminar-flow hoods was also measured, since some of the metal in the interior of the older hoods showed corrosion. An uncovered empty $50-\mathrm{ml}$ beaker was allowed to stand in the hood $24 \mathrm{~h}$, treated with acid and the iron measured polarographically $-0.55 \mu \mathrm{g}$ of iron was found. New laminarflow hoods, which were not corroded, were used for most steps in the analysis of the lunar samples.

Geochemists usually break the rock in an iron mortar then crush it further in a mortar (such as alumina, agate, etc.) to facilitate dissolution. The amount of iron contamination which would arise from the initial crushing in an iron mortar was determined. Pieces of a quartz container and pieces of the same quartz container which had been first broken in an iron mortar then crushed in an agate mortar were analyzed polarographically. Values of $2.6 \mathrm{ppm}$ of iron were obtained for the uncrushed quartz, and $81.7 \mathrm{ppm}$ of iron were found in pieces broken in an iron mortar.

Since nickel would probably be extracted with dimethylglyoxime from the solution remaining after extraction of iron and titanium, it was also determined in the same lunar sample. Aluminum could also be determined on the same sample by extraction, but it was not done at this time.

\section{Lunar Sample 14163, 159 (Fine Soil)}

Duplicate samples were weighed into small platinum boats on the semimicro balance in the Analytical Mass Spectrometry Section clean room. Although the original plan had called for duplicate 5-mg samples, it was difficult to obtain the same weights for this small amount, and one 5- and one 10-mg sample were taken. The volumes of reagents used for the $10-\mathrm{mg}$ sample were twice that described in the procedure below and the final dilution volume was $50 \mathrm{ml}$. The samples were placed in desiccators, transferred to the balance room and weighed on a microbalance. They were then transferred to $100-\mathrm{ml}$ Teflon beakers containing $2 \mathrm{ml}$ of water and covered with Teflon lids. The beakers were wrapped with a wet towel and handled with wet nylon gloves in order to minimize the static charge usually present with Teflon beakers. The walls were washed down with several $\mathrm{ml}$ of distilled water and the platinum boats were reweighed.

The samples were placed in laminar-flow hoods in the laboratory where the chemical processing was done. Ten drops of hydrofluoric acid and 2 drops of perchloric acid were added and the samples were dissolved and heated overnight on a hot plate $(\sim 90-$

\footnotetext{
${ }^{2}$ Certain commercial materials are identified in this paper in order to adequately specify the experimental procedure. Such identification does not imply recommendation or endorse ment by the National Bureau of Standards.
}

$95{ }^{\circ} \mathrm{C}$ ). Two additional drops of perchloric acid were added and the cover and sides were washed down with water. The solutions were evaporated to dryness, 1 drop of perchloric acid was added, the cover and sides were washed down with water, and the solutions were again evaporated to dryness. Five drops of hydrochloric acid were added, the cover and sides again washed down, the solutions evaporated to dryness and the process repeated once more. The residues were then dissolved in $1 \mathrm{ml}$ of $9 \mathrm{M} \mathrm{HCl}$, sides and cover washed down with water, and a few crystals of boric acid were added to complex any fluoride remaining. The solutions were boiled and transferred to a separatory funnel with a minimum amount of water, keeping the final volume below $10 \mathrm{ml}$. One $\mathrm{ml}$ of 6 percent cupferron solution, filtered and cooled in ice, was added and iron and titanium were extracted into quartz beakers with $15 \mathrm{ml}$ of ice-cold chloroform. The extraction was repeated 3 times with $10-\mathrm{ml}$ portions of chloroform with $0.5 \mathrm{ml}$ of 6 percent cupferron being added before the third extraction. The extracts were reserved for the determination of iron and titanium.

The nickel was extracted from the solution remaining in the separatory funnel by adding $0.5 \mathrm{ml}$ of 20 percent hydroxylamine hydrochloride solution, $1 \mathrm{ml}$ of 1 percent dimethylglyoxime solution (in alcohol) and 1 drop of methyl red. Ammonium hydroxide was added to neutralize the solution, plus about 3 drops in excess. The nickel was then extracted with 15-, 10-, and 5-ml portions of chloroform and the extracts reserved for later determination.

The chloroform extracts containing the iron and titanium were evaporated to dryness at room temperature in the laminar-flow hood. The organic material was destroyed by repeated fumings with nitric acid, $9 M$ hydrochloric acid and perchloric acid using a total volume of $3.5 \mathrm{ml}$ of nitric acid, $1 \mathrm{ml}$ of hydrochloric acid, and $1.5 \mathrm{ml}$ of perchloric acid. After evaporation to dryness, the residues were dissolved in $1 \mathrm{ml}$ of $9 M$ hydrochloric acid and evaporated to dryness again at about $90{ }^{\circ} \mathrm{C}$. One $\mathrm{ml}$ of $1+1 \mathrm{H}_{2} \mathrm{SO}_{4}$ (v/v) and about $5 \mathrm{ml}$ of water were added and the solution heated for several hours at just under boiling, replenishing the water as needed. Ten $\mathrm{ml}$ of a mixture of $0.2 M$ EDTA- $0.2 M$ sodium acetate solution was added and the $\mathrm{pH}$ was adjusted to 4 . The solutions were then diluted to $25 \mathrm{ml}$. All standardization aliquots and all dilutions for iron and titanium were made by weight on a semimicro balance. The solutions were transferred to polarographic cells, deaerated with argon for about $10 \mathrm{~min}$ and iron and titanium measured polarographically in the subtractive mode of operation with the blank in the second cell. Iron was measured at about -0.3 and titanium at about $-0.5 \mathrm{~V}$ versus a mercury pool anode.

The nickel extracts were evaporated to dryness at room temperature in the laminar-flow hood. Organic material was destroyed by evaporating to dryness twice with perchloric and nitric acids. The residues were dissolved in 5 drops of $9 M$ hydrochloric acid and evaporated to dryness at about $90{ }^{\circ} \mathrm{C}$. The residues were then dissolved by heating with $0.2 \mathrm{ml} \mathrm{l}+1$ 
sulfuric acid (v/v) and about $2 \mathrm{ml}$ of water. One $\mathrm{ml}$ of pyridine was added and the solutions diluted to $5.0 \mathrm{ml}$. The solutions were transferred to polarographic cells, deaerated about 10 min with argon and measured polarographically at about $-1 \mathrm{~V}$ versus a mercury pool anode in the subtractive mode of operation, with the blank in the second cell. Calibration reference solutions of nickel, which had been carried through the entire procedure, were measured in the same way.

\section{Lunar Sample 14321,221 (Rock)}

The sample which was received in a Teflon bag was hit once while still in the bag with a steel Teflonwrapped pestle to break the rock into smaller fragments. A portion of the sample weighing approximately $4 \mathrm{~g}$ was transferred to a Teflon bomb encased in steel. Eight grams of perchloric acid and $7 \mathrm{~g}$ of hydrofluoric acid were added and the bomb was heated overnight at $150{ }^{\circ} \mathrm{C}$. The solution portion was decanted into a Teflon beaker, and the remaining residue was heated in the bomb overnight at $150{ }^{\circ} \mathrm{C}$ with $5.8 \mathrm{~g}$ of perchloric acid and $6.0 \mathrm{~g}$ of hydrofluoric acid. The solutions were combined in a Teflon beaker, evaporated and fumed with perchloric acid several times to convert fluoride to perchlorate, and then fumed almost to dryness. The solutions were diluted to volume by weight and weighed aliquots were transferred to Teflon beakers. The remainder of the procedure was essentially the same as already described for the fine soil.

\section{Results}

Sufficient sample of the rock was available for three separate aliquots for iron and titanium. One aliquot was run directly without a cupferron extraction to obtain first an approximate iron and titanium concentration range and the other two were run as described in the procedure above. The results are shown in table 1.

TABLE 1. Polarographic determination of iron and titanium in Apollo 14 samples and USGS AGV-1

\begin{tabular}{l|c|c|c|c}
\hline \hline \multicolumn{1}{c|}{ Sample } & \multicolumn{2}{|c|}{ Iron* } & \multicolumn{2}{c}{ Titanium* } \\
\hline & $\mu g$ & Percent & $\mu g$ & Percent \\
$14163,159(1)$ & 401 & 7.74 & 50.5 & 0.975 \\
$14163,159(2)$ & 812 & 7.74 & 103.0 & 0.981 \\
$\quad$ Average & & 7.74 & & 0.978 \\
14321, 221 (1)(direct) & 739 & 11.53 & 83.8 & 1.31 \\
14321, 221 (2) & 947 & 11.44 & 106.9 & 1.29 \\
14321, 221 (3) & 1004 & 11.53 & 115.7 & 1.33 \\
$\quad$ Average & & 11.50 & & 1.31 \\
AGV-1 & 389 & 4.78 & & \\
\hline
\end{tabular}

* Represents total iron or titanium in sample regardless of oxidation state.

An iron blank of about $0.5 \mu \mathrm{g}$ was found. The points for the standard calibration curves for iron showed excellent linearity in the region plotted and also bracketed the concentration ranges of the samples. The calibration curve for titanium in the lunar soil, however, was exceedingly nonlinear as incomplete recovery was obtained for the titanium reference points. The titanium values for this sample were therefore calculated using the average value of titanium in AGV-1 as a standard reference point. The nonlinearity has not yet been explained as this difficulty had never occurred previously. The subsequent titanium calibration curves run with the rock verified the validity of the AGV-1 calibration factor. The direct run gives essentially the same results as the samples which were separated with cupferron.

The results for nickel are shown in table 2 .

TABLE 2. Polarographic determination of nickel in Apollo 14 samples and USGS AGV-1

\begin{tabular}{c|c|c}
\hline \hline Sample & \multicolumn{2}{|c}{$\mathrm{Ni}$} \\
\hline & $\mu g$ & $p p m$ \\
$14163,159(1)$ & 1.70 & 329 \\
$14163,159(2)$ & 3.54 & 337 \\
average & & 333 \\
$14321,221(2)$ & 1.20 & 145 \\
$14321,221(3)$ & 1.26 & 145 \\
average & & 145 \\
AGV-1 & 0.16 & 19.7 \\
\hline
\end{tabular}

The standard deviation for 14163 is about $6 \mathrm{ppm}$ or 2 percent. The average nickel value reported for the U.S. Geological Survey sample AGV-1 is $17.8 \mathrm{ppm}$. However, the good agreement for AGV-1 can only be considered fortuitous since the amount of nickel present was not enough to give a well-defined reduction peak.

Some preliminary work was also undertaken for the development of a polarographic method for the simultaneous determination of bismuth, copper, thallium, lead, and cadmium in lunar samples. When 1-g samples of U.S. Geological Survey sample BCR-1 was taken through the procedure, results of $0.1 \mathrm{ppm}$ bismuth, $0.1 \mathrm{ppm}$ thallium, $20 \mathrm{ppm}$ copper, $15 \mathrm{ppm}$ lead, and $0.05 \mathrm{ppm}$ cadmium were obtained. The average values which have been reported for these elements are $<0.5 \mathrm{ppm}$ bismuth, $0.36 \mathrm{ppm}$ thallium, $22.4 \mathrm{ppm}$ copper, $18 \mathrm{ppm}$ lead, and $0.067 \mathrm{ppm}$ cadmium, [6]. The polarographic reduction peaks for bismuth, cadmium, and thallium were small and ill-defined, necessitating further work to improve the method, however the method for copper and lead is felt to be reliable in these concentration levels.

A portion of this work was sponsored by NASA under Contract No. T-1799A.

The author would also like to thank the Principal Investigator W. R. Shields, co-investigators T. J. Murphy, L. A. Machlan, I. L. Barnes, and co-workers for making available pure reagents, part of the clean room facilities, and helpful advice. 


\section{References}

[1] Maienthal, E. J., and Taylor, J. K., Anal. Chem. 35, 1516 (1965).

[2] Maienthal, E. J., Polarographic Analysis, Nat. Bur. Stand. (U.S.), Tech. Note 505, p. 17 (Oct. 1969).

[3] Maienthal, E. J., Polarographic Analysis, Nat. Bur. Stand. (U.S.), Tech. Note 545, p. 41 (Dec. 1970).

[4] Maienthal, E. J., and Taylor, J. K., in Trace Inorganics in Water, pp. 172-182, Advances in Chemistry Series 73, Am. Chem. Soc. (1968).
[5] Trace Elements in a Glass Matrix, Certificate of Analysis (provisional), Standard Reference Materials 610 through 619. Available from Office of Standard Reference Materials, National Bureau of Standards, Washington, D.C. 20234.

[6] Flanagan, F. J., Geochim. et Cosmochim. Acta 33, 81 (1969).

[7] Abbey, S., Canadian Spectroscopy 15, 2 (1970).

(Paper 76A5-739) 